\title{
A pesquisa na biblioteca da Fundacentro na produção científica em segurança e saúde no trabalho: um estudo de caso
}

Mauro Maia Laruccia

Docente-pesquisador da Faculdade de economia e administração da PUC/SP e do Mestrado em Comunicação e Cultura da UNISO

Sergio Roberto Cosmano

Bibliotecário da Fundação Jorge Duprat Figueiredo de Segurança e Medicina do Trabalho

- Fundacentro

Roberta Galasso Nardi

Professora da Universidade de São Paulo

http://dx.doi.org/10.1590/1981-5344/1274

Este trabalho tem como objetivo analisar a contribuição da biblioteca na produção científica da Fundacentro. Utilizou-se o método survey de pesquisa para levantar os dados e abordagem qualitativa na discussão. Os resultados demonstraram que a biblioteca da Fundacentro atende às expectativas dos usuários da Instituição tanto no CTN e regionais, mas há alguns pontos que precisam ser revistos e melhorados, a fim de que ofereça plena satisfação aos pesquisadores, servidores e colaboradores e, também, a todos aqueles que se utilizam da biblioteca física ou online, bem como de seus produtos e serviços, para realização de seus trabalhos ou nas suas produções científicas.

Palavras-chave: Biblioteca; Linguagens e Tecnologias; Informação e Conhecimento; Interdisciplinar.

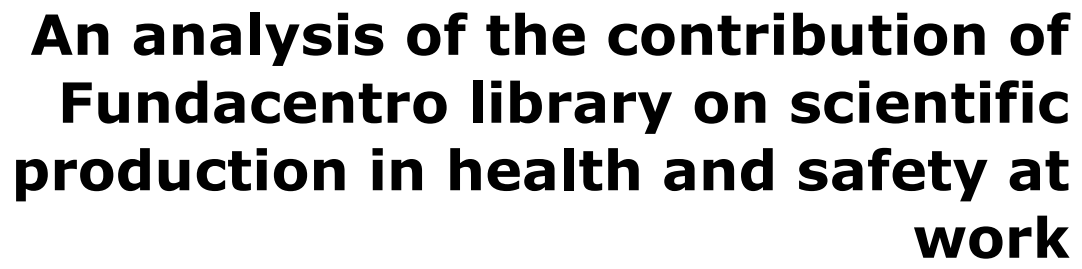


This study aims to analyze how it carries out research in the Fundacentro library of related to scientific production in health and safety at work. We used survey research to obtain and qualitative approach. The results showed that the Fundacentro library meets users' expectations in both CTN and regional, but there are some observed points that need to be reviewed and improved in order to receive satisfaction from researchers, servants and employees, and all those who use the physical library or online, and its products and services to perform their jobs or their scientific productions.

Keywords: Library; Languages and Technologies; Information and Knowledge; Interdisciplinary.

Recebido em 07.07.2014 Aceito em 01.09.2014

\section{Introdução}

Este trabalho tem como objetivo analisar como se realiza a pesquisa na biblioteca da Fundacentro na produção científica em segurança e saúde no trabalho, por meio de um estudo de caso. Pretende-se analisar a percepção dos pesquisadores sobre a biblioteca da Fundação Jorge Duprat de Segurança e Medicina do Trabalho (Fundacentro) e, aqui, considerados usuários do ambiente físico e virtual da biblioteca, particularmente, para produção cientifica em segurança e saúde no trabalho (SST).

A biblioteca do futuro, para os pesquisadores, não será necessariamente uma "biblioteca eletrônica", nem terá a missão de preservar simplesmente o conhecimento registrado. Ela terá como objetivo, mais apropriadamente, a geração, a preservação e a melhoria do pronto acesso físico e intelectual à informação relevante para seus usuários (CONWAY, 2001), cujo desafio da mudança é uma oportunidade de renovação para a biblioteca (CUNHA, 2008).

O desenvolvimento e os avanços tecnológicos e informacionais fizeram surgir vários tipos de bibliotecas, bem como mudanças estruturais nas suas funções (FIGUEIREDO, 1996). Para que o ambiente de pesquisa atenda às necessidades informacionais $e$ às expectativas dos pesquisadores, as fontes disponíveis para realização de suas pesquisas devem ser claras, de interface adequada, usabilidade e interatividade satisfatória. O acesso a esses conteúdos, as informações contidas tanto na biblioteca física como na online, deve atender às necessidades em diversos sentidos, como qualidade da informação, conteúdo, pertinência, rapidez e acessibilidade facilitada.

As bibliotecas físicas estão se transformando, ao longo dos anos, devido ao enorme aumento informacional e à evolução tecnológica e, com essas transformações, surge a necessidade de repensar a maneira como disponibilizar a informação, visto que uma série de fatores precisa ser avaliado, logo, as bibliotecas tradicionais (físicas) têm que rever sua 
forma de atuar. Para a busca pela informação, ficam obrigadas as bibliotecas ou os centros de informação a rever a forma de atendimento dos seus usuários, a providenciar e facilitar o acesso ao conteúdo informacional (KROEF, 2009), com eficiência e eficácia.

Os sistemas de informação somente serão eficazes quando se identificarem clara e cuidadosamente os perfis dos respectivos usuários e das organizações. Acrescente-se a isso a importância de conhecer em profundidade o negócio de cada organização, ou seja, como os indivíduos utilizam a informação. Para a criação de um sistema de informação que auxilie a geração de conhecimento é necessário saber onde se encontram as fontes de conhecimento na organização, como é criado esse conhecimento e como transmiti-lo (SANTOS; VERGUEIRO, 2002).

De sua parte, devido ao desenvolvimento informacional, os pesquisadores têm sentido a necessidade de novas ferramentas na busca e tratamento da informação para gerar novos conhecimentos. Para suprir essas necessidades, as bibliotecas físicas buscam adequar-se à nova realidade, mas, para isso, é necessário ouvir o pesquisador para descobrir quais as ferramentas e as fontes de busca necessárias que facilitam o acesso informacional relacionado com as suas produções científicas. 0 pesquisador pode, também, contar com a participação do bibliotecário um mediador e facilitador do acesso à informação (MARCELINO, 2008).

Fonseca (2007, p. 49) observa que:

Inicialmente considerada no planejamento educacional, a biblioteca é hoje encarada pelos planejadores "como parte integrante dos meios de comunicação de massa", como ficou estabelecido pelos participantes de reuniões promovidas pela UNESCO em Lima (1973) e Turrialba, na Costa Rica (1974) ${ }^{1}$. Seu planejamento inclui, necessariamente a formação de coleções segundo rigoroso critério seletivo, direcionado para os usuários de cada categoria de biblioteca. Por isso Ortega y Gasset imaginava "o futuro bibliotecário como um filtro que se interpõe entre a torrente de livros e o homem" $E$ Jorge Luis Borges disse num poema: 'Ordenar bibliotecas é exercer, de modo silencioso e modesto, a arte da critica'.

Em 2000, Cunha justificava o incremento do interesse pelos estudos sobre as bibliotecas e centros de informações, afirmando que isso, talvez, se devesse ao rápido processo de mudanças nas áreas científica, tecnológica, econômica, política e social e à aproximação do início de novos século e milênio (CUNHA, 2000).

$\mathrm{Na}$ sociedade da informação e do conhecimento, a biblioteca, segundo Behr, Moro e Estatel (2008),

${ }^{1} \mathrm{O}$ eventos foram realizados nas cidades de Lima e Turrialba em Costa Rica, conforme apontado por Fonseca (2007, p. 49). 
[...] ocupa um espaço significativo no que concerne às suas metodologias, enfoques e aplicação de ferramentas de gestão e serviços. Nas diretrizes da biblioteca no sistema educacional, a gestão em serviço de bibliotecas [...] deve priorizar a aprendizagem em todo o processo de desenvolvimento humano, além do acesso e uso da informação (BEHR; MORO; ESTATEL, 2008, p. 32).

As metodologias e ferramentas de gestão, com certeza, contribuirão para os resultados eficientes e eficazes dos serviços oferecidos com enfoque na biblioteca, no bibliotecário, nos serviços de qualidade e no usuário. A gestão preconiza a qualidade de serviços com foco na eficiência e na eficácia, buscando a rapidez e o resultado satisfatório que atenda às necessidades de informação dos usuários.

\section{A Biblioteca da Fundacentro}

A Fundação Jorge Duprat de Segurança e Saúde do Trabalhador (Fundacentro) teve os primeiros passos de sua história no início da década de 1960, quando a preocupação com os altos índices de acidentes e doenças do trabalho crescia no governo e entre a sociedade e o governo brasileiro iniciou gestões com a Organização Internacional do Trabalho (OIT), com a finalidade de promover estudos e avaliações do problema e apontar soluções que pudessem alterar esse quadro (FUNDACENTRO, 2006).

A Fundacentro realiza diversos projetos na área de SST. Para isso, dispõe de uma rede de laboratórios em segurança, higiene e saúde no trabalho e de uma das mais completas bibliotecas especializadas, além de profissionais formados em várias áreas, muitos deles pós-graduados no Brasil e exterior.

A biblioteca tem como objetivo disseminar informações sobre segurança e saúde no trabalho, aos pesquisadores da área, bem como à comunidade em geral; promover o acesso à informação concernente à área de SST e oferecer apoio às atividades de normatização, pesquisa e recuperação informacional. Atende aos usuários internos e externos interessados na área de Segurança e Saúde no Trabalho, facilitando o acesso à informação, à produção técnico-científica e à divulgação das informações em SST, tanto no formato impresso como eletrônico, através do portal da Fundacentro.

\section{Procedimentos metodológicos}

Com relação à metodologia da pesquisa, foi dividida em três categorias de tipologia de pesquisa (RAUPP; BEUREN, 2006): quanto aos objetivos, foi utilizada a pesquisa descritiva; quanto aos procedimentos, foi utilizada o levantamento de dados ou survey para os dados primários; e quanto à abordagem do problema, trata-se de uma pesquisa qualitativa, disponibilizada no endereço http://www.Qualtrics.com/, de 23 de setembro a 23 de outubro de 2010, com o objetivo de verificar como a biblioteca 
poderá contribuir para a produção científica na Fundacentro e/ou para o desenvolvimento de seu trabalho. Para McDaniel e Gats (2003), com o uso de questionários na internet, os entrevistados completam a pesquisa e os dados são automaticamente coletados e tabulados.

Para a coleta de dados por meio do questionário, foram enviadas 539 mensagens por e-mail aos funcionários da Fundacentro, buscando-se receber um retorno de $10 \%$ do total de funcionários e colaboradores. 0 total de respondentes foi de 109, ou seja, a pesquisa de campo apresentou uma amostra de 20,2\% (vinte vírgula dois por cento) da população total que obteve o acesso para a efetivação da pesquisa. Desses 109 respondentes, 87 responderam todas as questões. Esse procedimento aconteceu no mês de outubro de 2010.

\section{Análise dos Resultados}

$\mathrm{Na}$ análise das respostas referentes à questão como a biblioteca da Fundacentro contribui na sua produção científica e/ou para o desenvolvimento de seu trabalho, foram separados os elogios das críticas e sugestões, para reflexão e realizações de ações futuras que venham atender na totalidade ou em partes às solicitações dos usuários, que muito contribuíram com suas colocações.

Responderam esta questão 60 participantes da pesquisa. As respostas foram transcritas de acordo com o que responderam os usuários, não sendo, de forma alguma, alterado o conteúdo. Foram mantidos os erros de português, tamanho e formato da fonte, procurou-se manter a originalidade dos escritos.

As respostas de números $1,12,17,21,22,30,32,33$ e 48 foram separadas, por serem respondidas de forma neutra, ou seja, são respostas nas quais não se observa a conotação da pergunta, que é: como biblioteca da Fundacentro contribui na sua produção científica e/ou para o desenvolvimento de seu trabalho? Desta maneira, essas respostas não se encaixam como elogios, críticas ou sugestões, podendo ser consideradas neutras.

Em nada. (Respondente 1).

A Biblioteca permite, além de tantos serviços oferecidos, o intercâmbio com outras bibliotecas. (Respondente 12).

Não a utilizo muito. Faço minhas pesquisas online ou livros que eu mesma compro. (Respondente 17).

Eu contribuo com parte da ampliação dela e acho que tudo é bem organizado. (Respondente 21). 
Com o acesso de conteúdos importantes. (Respondente 22).

Neutro. (Respondente 30).

A Biblioteca é fundamental, pois adquirimos conhecimento que não temos. (Respondente 32).

contribui com um bom material de pesquisa para 0 desenvolvimento dos trabalhos. (Respondente 33).

Ela é muito importante. (Respondente 48).

Os Respondentes 3 e 4, afirmam que a biblioteca está cumprindo o seu papel no fornecimento de subsídios, sendo, também, consideradas ferramentas fundamentais, impossível de se trabalhar sem eles.

Cumprindo o papel de uma Biblioteca no fornecimento de subsídios. (Respondente 3).

É Ferramenta fundamental. Sem ela não é Possível trabalhar. (Respondente 4).

Os respondentes 5, 7 e 11 afirmaram que, com os materiais disponíveis no acervo e com o bom atendimento dado pelos bibliotecários, recebem auxílio para encontrar os materiais necessários à pesquisa:

No desenvolvimento de trabalho tenho as informações necessárias para realizar as atividades e também que a biblioteca me auxilia, principalmente via online no levantamento bibliográfico. Com os materiais disponíveis no acervo e com o bom atendimento dado pelos bibliotecários, auxílio para encontrar os materiais necessários à pesquisa. (Respondente 5 ).

No desenvolvimento do meu trabalho tenho as informações necessárias para realizar as atividades. (Respondente 7).

A biblioteca me auxilia principalmente via online no levantamento bibliográfico. (Respondente 11).

Os respondentes $14,15,18$ e 19 afirmaram que sempre que precisaram de um material, encontraram na biblioteca, considerando a 
biblioteca da Fundacentro de fundamental importância para o desenvolvimento de seus trabalhos e daqueles de militam na área de Segurança e Saúde do Trabalhador. Também é considerada uma biblioteca atualizada na área, sendo muito útil para realização de suas pesquisas. Não deixaram de salientar que conseguem desenvolver melhor o seu trabalho, graças à organização excepcional do material (disponível para consulta e material do site) e que, hoje em dia, as pessoas buscam agilidade e bom atendimento. E, ainda, enfatizaram que a biblioteca contribuiu para aumentar seus conhecimentos técnico e científico.

Sempre que precisei de uma material encontrei na biblioteca. A biblioteca da é de fundamental importância para o desenvolvimento do nosso trabalho e daqueles de militam na área de Segurança e Saúde do Trabalhador. (Respondente 14).

è uma biblioteca atualizada na área, sendo muito útil para realização das minhas pesquisas. (Respondente 15).

Consigo desenvolver melhor o meu trabalho graças a organização excepcional do material (disponível para consulta e material do site), hoje em dia as pessoas buscam agilidade e bom atendimento, e graças a essa organização e competência dos bibliotecários consigo desenvolver o meu trabalho da melhor maneira possível. (Respondente 18).

Contribuiu para aumentar o conhecimento técnico e científico. (Respondente 19).

Para o respondente de número 20, a grande maioria do material necessário para seus trabalhos, é obtido na biblioteca da Fundacentro ou por outros centros de pesquisas. Isso significa que a biblioteca tem atendido às suas expectativas, pelo menos em parte.

A maioria do material para os meus trabalhos são obtidos na biblioteca ou por ela em outras centros de pesquisas. (Respondente 20).

Em relação aos respondentes 23, 24, 25, 26, 27, 28 e 29, foi dito que a biblioteca da Fundacentro, por disponibilizar uma boa quantidade de seu acervo online com informações relevantes, auxilia muito nas conclusões de pesquisas. Também, outro usuário disse que a biblioteca possui um ótimo acervo sobre as áreas de segurança e saúde no trabalho, podendo aumentar seu acervo online. Outros dizem que contribui de uma forma muito boa, tanto na produção científica quanto no desenvolvimento de seu trabalho diariamente, porque há uma excelente equipe técnica e os recursos informacionais são excelentes e, também, que ao fornecer bons e 
satisfatórios serviços de levantamento bibliográfico, acesso a artigos e livros atualizados, sua contribuição é extremamente relevante.

A biblioteca Fundacentro por disponibilizar uma boa quantidade de seu acervo online auxilia muito nas conclusões de pesquisas de seus usuários. (Respondente 23).

Contribui de uma forma muito boa tanto na produção científica quanto no desenvolvimento do meu trabalho. (Respondente 24).

A biblioteca possui um ótimo acervo sobre as áreas de segurança e saúde no trabalho, podem também aumentar seu acervo online. (Respondente 25).

A Biblioteca contribui diariamente porque tem excelente equipe técnica e os recursos informacionais, também, são excelentes. (Respondente 26).

Ao fornecer bons serviços de levantamento bibliográfico, acesso a artigos e livros atualizados sua contribuição é extremamente relevante. (Respondente 27 ).

Com informações relevantes. (Respondente 28).

Satisfatoriamente na área de levantamento bibliográfico. (Respondente 29).

Para os respondentes $31,35,37,40,41,43,47,49,51,56,57$ e 58 , respectivamente, a biblioteca contribui para realização de pesquisas em SST; utiliza sempre que necessita de informações na área SST; a biblioteca ajuda usuários para o entendimento de diversos artigos no serviço diário; a biblioteca atende bem, por meio de pesquisa/levantamento bibliográfica, correção de referência bibliográfica e acesso a literatura; a biblioteca é extremamente importante para o trabalho tanto de Mestrado como de resposta a consultas técnicas; por meio de realização de levantamentos bibliográficos sobre os assuntos de interesse e enviando o material por empréstimo ou cópia do mesmo; contribui de forma muito positiva; de forma satisfatória; por meio das pesquisas o usuário salienta ter mais informações sobre os trabalhos que precisa desenvolver; é sempre bem atendida pelos funcionários da biblioteca; que os livros são bastante importantes seu estudo de graduação e auxílio para os trabalhos da pós-graduação lato-sensu. 
Pesquisas em SST, utilização da sala de reunião. (Respondente 31).

Para o desenvolvimento do meu trabalho e pesquisa sempre que necessito de informações na área SST. (Respondente 35).

A biblioteca me ajuda para o entendimento de diversos artigos para o meu serviço diário. (Respondente 37 ).

Bem (Respondente 40).

Por meio de pesquisa/levantamento bibliográfica, correção de referência bibliográfica, acesso a literatura (Respondente 41).

A biblioteca é extremamente importante para o meu trabalho tanto de Mestrado como de resposta a consultas técnicas. (Respondente 43).

Realizando levantamentos bibliográficos sobre os assuntos de interesse e enviando o material por empréstimo ou cópia do mesmo. (Respondente 47).

Contribui de forma muito positiva. (Respondente 49).

De forma satisfatória (Respondente 51).

Através das pesquisas tenho mais informações sobre os trabalhos que preciso desenvolver. (Respondente 56).

Sou sempre bem atendida pelos funcionários da biblioteca. Os livros são bastante importantes para minha graduação. (Respondente 57).

Auxiliando para os trabalhos da pós-graduação latu-sensu (Respondente 58).

Os respondentes que fizeram suas críticas construtivas e deram sugestões foram 20 participantes. Nas citações dos respondentes 2, 6 e 8, foram respondidas que, no acesso, há algumas informações e dados 
específicos do campo da segurança e saúde do trabalhador. Entretanto, diante da agilidade, atualidade e disponibilidade de outras fontes existentes e, ainda, da defasagem atual do acervo, a contribuição tem sido modesta. Outro disse que contribui mais em relação ao empréstimo de livros. Existiram sugestões de que seria muito importante se novas bases de dados e de acesso a periódicos e livros eletrônicos fossem disponibilizadas. Como sugestão também, foi dito que se a biblioteca possuísse acesso aos bancos de dados de periódicos, como existe na USP, onde se pode acessar os periódicos online, de qualquer computador na rede, a contribuição seria infinitamente maior.

No acesso a algumas informações e dados específicos do campo da segurança e saúde do trabalhador. Entretanto, diante da agilidade, atualidade e disponibilidade de outras fontes existentes, e da defasagem atual do acervo, a contribuição tem sido modesta. (Respondente 2).

Mais em relação ao empréstimo de livros. Seria muito importante se novas bases de dados e de acesso a periódicos e livros eletrônicos fossem disponibilizadas. (Respondente 6).

se a biblioteca possuísse acesso aos bancos de dados de periódicos, como existe na USP, onde se pode acessar os periódicos on-line de qualquer computador na rede, a contribuição seria infinitamente maior. (Respondente 8).

Os respondentes das questões de números 9, 12, 13 e 16, disseram que a biblioteca tem papel fundamental na atividade de pesquisa e de difusão de informações e que o acervo especializado em SST é o seu maior patrimônio, o que justifica a sua existência. Mas, é comentado que a biblioteca está precisando de um grande investimento para a manutenção e atualização e modernização do acervo. Foi dito que a era online ainda é muito primária na biblioteca, o que hoje é inadmissível.

Quanto ao acervo, ele deve ser digitalizado e mantido atualizado constantemente e os sistemas de busca têm que ser mais ágeis. Também foi sugerido que a biblioteca faça parcerias e/ou contratação serviços de organização de documentos e de acessos à informação eficientes e atualizados. Foi dito que faltam investimentos em tecnologia, pessoal, inclusive, material bibliográfico. E foi sugerido que, talvez, pudesse ser apresentada proposta de financiamento à FAPESP ou a outras agências semelhantes, para modernizar a biblioteca, com um projeto bem elaborado por uma empresa especializada.

A biblioteca contribui de forma relevante, mas poderia, ao realizar a busca por palavras chave, exibir as referências no formato da norma 6023, de referências bibliográficas. Embora nunca tenha ficado clara qual a diferença entre uma pesquisa livre e outra estruturada, nem como e em 
quais circunstâncias uma seria melhor do que a outra, o serviço serve de apoio aos trabalhos desenvolvidos, mas, certamente, o serviço pode ser melhorado na disponibilidade online de documentos.

Faz-se um adendo, quando foi sugerido que a biblioteca faça parcerias e/ou contratação serviços de organização de documentos (isso já acontece na biblioteca), visto que os materiais são processados, classificados, organizados e armazenados da forma mais rigorosa possível. Quanto às referências aparecerem no formato da norma NBR 6023 (ASSOCIAÇÃO BRASILEIRA DE NORMAS TÉCNICAS, 2002), de referências bibliográficas, isso seria interessante rever a forma de exibição dos dados após a busca. $\mathrm{E}$, também, pode ser melhorado, conforme salienta o usuário que o site de busca na pesquisa livre e estruturada deve esclarecer melhor os usuários quanto às vantagens e desvantagens, tanto de uma como de outra forma de pesquisa.

Quanto a adquirir mais títulos, teses e dissertações defendidas sobre as questões de saúde e trabalho, é interessante, promovendo o enriquecimento do acervo.

A biblioteca tem papel fundamental na atividade de pesquisa e de difusão de informações. O acervo especializado em SST é o seu maior patrimônio. É principalmente esse acervo que justifica a sua existência e estrutura física. No entanto a biblioteca está precisando de um grande investimento para a manutenção e atualização do acervo e para sua modernização. A era 'online' ainda é muito primária na nossa Biblioteca, o que hoje é inadmissível. O acervo tem que ser digitalizado e ser mantido constantemente atualizado. Os sistemas de busca têm que ser mais ágeis. A Biblioteca tem que fazer parcerias e/ou contratar serviços de organização de documentos e de acessos à informação eficientes e atualizados. Faltam investimentos em tecnologia, pessoal e material, inclusive material bibliográfico. Talvez pudesse ser apresentada proposta de financiamento à FAPESP, ou outras agências semelhantes, para modernizar a biblioteca, com um projeto bem elaborado por empresa especializada. (Respondente 9).

A biblioteca contribui de forma relevante, mas poderia ao realizar a busca por palavras chave, as referencias aparecer no formato da norma 6023, de referencias bibliográficas. (Respondente 10).

Embora nunca tenha ficado claro qual a diferença entre uma pesquisa livre e outra estruturada nem como e em quais circunstâncias uma seria melhor do que a outra, o serviço serve de apoio aos trabalhos desenvolvidos mas certamente pode ser melhorado na disponibilidade online de documentos (Respondente 13). 
Considero importante adquirir mais títulos, teses e dissertações defendidas sobre as questões de saúde e trabalho (Respondente 16).

Os respondentes das questões de números 34, 36, 38, 39 e 42 salientaram que, nas regionais, a quantidade de assuntos é pequena ou inexistente, dependendo do CTN, o que dificulta a pesquisa.

Também, foi dito que todas as atividades de pesquisa sempre tiveram a contribuição da equipe da biblioteca, de forma eficiente, dedicada, com boa vontade, correta, com qualidade técnica inquestionável, mas um respondente sugeriu, porém, que é necessário investir mais em recursos tecnológicos nessa área, bem como providenciar mais recursos humanos.

Outro respondente diz que contribui muito, mas a sua sugestão principal se refere à melhoria na forma com que são apresentados os documentos, procurados por palavra chave e escreve que, às vezes, aparecem vários documentos, em diversas páginas, sem uma ordem lógica. Por exemplo: alfabética ou por cronologia, e sugere que a pesquisa devia conter mais de uma palavra chave ou a palavra chave e a data, por exemplo. Em sua avaliação, isso ajudaria a encontrar o documento procurado.

Outro respondente salientou que, quando lança palavras chave e coloca o nome de autor, na maioria das vezes, tem dificuldades ou "não se tem resposta". Mas a biblioteca da Fundacentro, dentre esses respondentes, foi considerada importantíssima para o desenvolvimento de trabalhos, além de que seria importante voltar a ter acesso às estantes e aos livros, pois sentem muita falta. Falta de manipular livros e periódicos.

Nas regionais, as quantidades de assuntos são pequenas ou inexistentes o que dificulta a pesquisa. (Respondente 34).

Todos as minhas atividades de pesquisa sempre tiveram a contribuição da equipe da biblioteca, de forma eficiente, dedicada, com boa vontade, correta, com qualidade técnica inquestionável. Porém é necessário investir mais recursos tecnológicos nessa área, bem como providenciar mais recursos humanos. (Respondente 36).

Contribui muito. Mas a minha sugestão principal se refere a melhoria na forma com que são apresentados os documentos procurados por palavra chave. As vezes aparecem vários documentos, em diversas páginas, e sem uma ordem lógica, por exemplo alfabética ou por cronologia. Talvez se a pesquisa pudesse conter mais de uma palavra chave, ou a palavra chave e a data por exemplo, avalio que isto ajudaria a encontrar o documento procurado. (Respondente 38). 
Considero a biblioteca da Fundacentro importantíssima para o desenvolvimento de trabalhos. Gostaria de voltar a ter acesso as estantes e aos livros. Sinto muita falta. Por causa disso vou muito pouco a biblioteca. (Respondente 39).

Gostava antes de manipular livros e periódicos. Quando você lança palavras-chave e coloca o nome de autor, na maioria das vezes tenho dificuldades ou 'não se tem resposta'. (Respondente 42).

Referente aos respondentes 44, 45, 46 e 50, dizem sempre ser muito bem atendidos pelos servidores/funcionários da biblioteca/CTN. 0 que deixa a desejar é o site de busca, pois há poucos campos para cruzar assuntos; a pesquisa não aceita determinadas letras; diversos títulos não têm a localização em qual biblioteca está, o que dificulta entrar em contato com o responsável. $E$, o que é de péssima qualidade, é o atendimento, em relação à aquisição de publicações, sendo enviadas várias listagens solicitadas pelos técnicos de determinada regional, porém, nem sequer recebem alguma resposta por parte SDB. Salientam, ainda, que simplesmente as publicações jamais chegam, salvo raríssimas exceções. Dizem que o trabalho da biblioteca, de ambas as partes, fica desacreditado, além de que o acervo está antigo e defasado.

Outro respondente salienta que a biblioteca é uma importante fonte de informações e que tem utilizado o serviço de COMUT com frequência, sendo considerado de extrema utilidade. Quanto à velocidade na obtenção de artigos de periódicos não incluídos no acervo da Fundacentro, ele deve ser melhorada, assim como a disponibilização de um software gerenciador de referências bibliográficas para os pesquisadores e tecnólogos.

Outra usuária responde que por autuar em área que não é pesquisa, utiliza pouco a biblioteca. Mas registra que, todas as vezes que precisou, sempre foi muito bem atendida. Também registra que tem dificuldades na biblioteca online, mas crê que seja pela falta de prática e hábito e pondera que viu outras bibliotecas mais fáceis de pesquisar via internet, citando, exemplo, a biblioteca da Faculdade de Saúde Pública.

Também foi registrado por outro respondente que o acervo referente à Saúde do Trabalhador corresponde à sua expectativa, mas salienta, no entanto, que deveria ser investido em acervo bibliográfico de outras áreas, como sociologia e antropologia.

O que deixa a desejar é o site de busca, onde há poucos campos para cruzar assuntos; a pesquisa não aceita determinadas letras; diversos títulos não tem a localização em qual biblioteca está, o que dificulta entrar em contato com o responsável... $E$, o que é de 'péssima' qualidade é o atendimento em relação a aquisição de publicações. Já foram enviadas várias listagens solicitadas pelos técnicos, porém, nem sequer recebemos alguma resposta por parte SDB. Simplesmente as publicações jamais chegam, salvo raríssimas exceções. O trabalho da biblioteca daí e daqui, fica desacreditado, além de que o acervo está antigo e defasado. Sobre as 
características da biblioteca/CTN não posso opinar (respondi uma ou 2 questões a esse respeito, por engano). (Respondente 44).

É uma importante fonte de informações. Tenho utilizado o serviço de COMUT com frequência, o que é de extrema utilidade. A velocidade na obtenção de artigos de periódicos não incluídos no acervo da FUNDACENTRO deve ser melhorada, assim como haver a disponibilização de um software gerenciador de referencias bibliográficas para os pesquisadores e tecnólogos. (Respondente 45).

Atuo em área que não é pesquisa, portanto utilizo pouco a biblioteca. No entanto, todas as vezes que precisei sempre fui muito bem atendida. Já necessitei de artigo que só tinha disponível em alguma biblioteca de regional, não me lembro o assunto que precisei e não estava disponível no CTN. Tenho dificuldade na biblioteca on-line, mas creio que seja pela falta de prática e hábito. mas já vi outras bibliotecas mais fáceis de pesquisar via internet, por exemplo a da Faculdade de Saúde Pública. (Respondente 46).

Em acervo referente à Saúde do Trabalhador, a biblioteca da instituição corresponde a expectativa. No entanto, creio que deveria ser investido em acervo bibliográfico de outros áreas, como sociologia, antropologia. (Respondente 50).

Os respondentes das questões de números 52, 54, 59 e 60, registraram que a biblioteca pouco contribui, pois não tem acesso online aos artigos completos de periódicos que costumam pesquisar.

Também foi registrado que a contribuição é inequívoca, pois possibilita 0 acesso a materiais produzidos pelos pesquisadores de diferentes áreas do conhecimento de forma atualizada e com embasamento técnico-científico. Em determinada regional, a biblioteca está fechada, devido à inexistência de profissional habilitado para atendimento ao público. E que muitos profissionais da capital, do interior do estado e estudantes de cursos de nível médio e superior em fase de pesquisa, que procuram este centro estadual e reclamam da situação atual da biblioteca, o respondente complementa, registrando que é o único espaço da região norte que possui vasto acervo especializado em Segurança e Saúde do Trabalhador. Este impasse, que está no limite, tem possibilitado a percepção da importância da biblioteca como um importante serviço prestado à construção de conhecimento na área de Segurança e Saúde do Trabalhador.

Outro registrou que contribui muito, só acredita que deveria ter profissionais (atendentes) mais preparados. E, por último, um respondente registrou que, nos últimos cinco anos, a biblioteca da Fundacentro pouco contribuiu com seus 
trabalhos, devido ao lento trâmite para aquisições, salientando que, quando necessário, compra os textos ou dirige-se às bibliotecas que possuem a base de periódicos da CAPES.

Pouco contribui, pois não tenho acesso on-line aos artigos completos de periódicos que costumo pesquisar. (Respondente 52).

A contribuição é inequívoca, pois possibilita o acesso a materiais produzidos pelos pesquisadores de diferentes áreas do conhecimento de forma atualizada e com embasamento técnicocientífico. Muitos profissionais da capital e do interior do estado e estudantes de cursos de nível médio e superior em fase de pesquisa que procuram este centro estadual reclamam da situação atual por ser a biblioteca o único espaço da região norte que possui vasto acervo especializado em Segurança e Saúde do Trabalhador. Este tem sido um limite e ao mesmo tempo tem possibilitado a percepção da importância da biblioteca como um importante serviço prestado á construção de conhecimento na área de Segurança e Saúde do Trabalhador. (Respondente 54).

Contribui muito, só acredito que deveria ter profissionais (atendentes) mas preparados (Respondente 59).

Nos últimos cinco anos, a biblioteca da Fundacentro pouco contribuiu com meus trabalhos. devido ao lento trâmite para aquisições, quando necessário eu mesmo compro os textos necessários ou me dirijo a bibliotecas que possuem a base de periódicos da CAPES. (Respondente 60).

Visto o resultado dos dados primários, a seguir, será realizada a discussão dos resultados.

\section{Considerações Finais}

O conhecimento científico em SST é de grande valia para aqueles que necessitam ter melhores condições de vida no ambiente de trabalho, portanto, deve ser produzido e disponibilizado o mais rápido possível, a fim de contribuir para a prevenção dos riscos e doenças ocupacionais. Nesse grupo, foram considerados os pesquisadores que, para desenvolver seus trabalhos, recorrem a dados e informações geralmente disponíveis em maior número e variedade nos ambientes de estudo, como as bibliotecas.

Devido ao incrível aumento informacional e à evolução tecnológica, reforça-se a necessidade de repensar a melhor maneira de disponibilizar a informação e rever a forma de atuar no atendimento dos usuários desses 
ambientes, especialmente para providenciar e facilitar o acesso ao conteúdo informacional com eficiência e eficácia.

A intenção desta pesquisa foi saber, especificamente, como a biblioteca contribui para a produção científica na Fundacentro, além de procurar conhecer, de forma mais completa, as necessidades e os pontos de vista dos seus pesquisadores, os quais necessitam buscar informações para as suas produções científicas em SST, além de analisarem o desenvolvimento de trabalhos dos servidores, colaboradores, estagiários e terceirizadas. Pode-se considerar de suma importância, verificar a ideia de consumo informacional dos pesquisadores, como eles adquirem a informação e pensam em relação às fontes disponíveis, opinando o que melhor lhes convém em contribuição às suas produções científicas.

Percebe-se que, nos últimos anos, crescem as reflexões em relação às bibliotecas e centros de informações, talvez, devido ao rápido processo de mudança nas áreas científica, tecnológica, econômica, política e social, devendo-se, no entanto, priorizar o acesso à informação, à aprendizagem e ao desenvolvimento intelectual, a fim de apoiar o avanço daqueles que necessitam produzir cientificamente, neste caso, os pesquisadores.

No decurso do estudo de caso, foi possível avaliar que a biblioteca satisfaz às necessidades dos usuários, mas, conforme se observou nas respostas dos sujeitos pesquisados, ainda cabe apontar a necessidade de se realizar algumas ações de melhoria.

Existem alternativas para a que as necessidades dos usuários possam ser supridas mais satisfatoriamente, propiciando, desta forma, aprofundar os seus conhecimentos. Seria viável, por exemplo, que a biblioteca realizasse cursos referentes a pesquisas bibliográficas em bases de dados existentes na biblioteca e nas bases online, a fim de que os interessados conheçam os valiosos recursos existentes na biblioteca. Além de esclarecer os usuários sobre o site de busca da biblioteca da Fundacentro, deveria haver, também, esclarecimentos sobre como realizar as pesquisas por palavras-chave, autor ou título da obra, de forma simples e estruturada.

Contudo, recomenda-se que, para qualquer tipo de investimento, seja ele tecnológico, humano, manutenção, atualização e modernização do acervo, além de material bibliográfico, é necessário sempre ouvir os usuários, visto que trabalhar de forma interdisciplinar, contribuirá para a escolha da melhor solução a tomar.

Deve-se, no entanto, por meio das sugestões registradas pelos usuários em relação à biblioteca online, rever a questão dos materiais online sugeridos para acesso, digitalizando o que for possível e manter esse registro constantemente atualizado, bem como cumpre melhorar o sistema de busca, para proporcionar mais agilidade.

O usuário gostaria de voltar a ter acesso às estantes e aos livros, pois sente muita falta de manusear esse material e, diante dessa impossibilidade, já não vai com tanta frequência à biblioteca.

Por último, um respondente registrou que, nos últimos cinco anos, a biblioteca da Fundacentro pouca contribuição deu aos seus trabalhos, 
devido ao lento trâmite para aquisições, e salienta que, quando necessário, compra os textos ou se dirige às bibliotecas que possuem a base de periódicos da CAPES.

Alguns respondentes sugeriram, também, que fosse apresentada à FAPESP ou a outras agências semelhantes, uma proposta de financiamento para modernizar a biblioteca, com um projeto bem elaborado por uma empresa especializada.

Para concluir, deve-se lembrar que a presente pesquisa apresenta algumas limitações, a saber: (a) trata-se de uma investigação empírica, aplicada aos pesquisadores, servidores e colaboradores da Fundacentro, no período de 23 de setembro a 23 de em outubro de 2010, na Fundacentro CTN-SP e regionais. Portanto, não se refere esta pesquisa a qualquer outro período de tempo, outra qualquer entidade, região geográfica ou objeto; (b) os pesquisadores foram convidados a responder questionários específicos, presumindo-se que as respostas obtidas foram dadas efetivamente pelos respondentes, a quem os questionários foram endereçados eletronicamente e expressam suas opiniões. Dessa forma, apenas este conjunto de respostas foi levado em conta; (c) os dados coletados foram analisados e considerados adequados à tipologia ordinal dos dados, pelo que os resultados das análises não levam em conta outras possíveis observações, fora do estudo proposto.

\section{Referências}

ASSOCIAÇÃO BRASILEIRA DE NORMAS TÉCNICAS (ABNT). NBR 6023: informação e documentação - referências - elaboração. Rio de Janeiro, 2002.

BEHR, A.; MORO, E. L. da. S.; ESTATEL, L. B. Gestão da biblioteca escolar: metodologias, enfoques e aplicação de ferramentas de gestão e serviços de biblioteca. Revista Ciência da Informação, Brasília, v. 37, n. 2, p. 32-42, maio/ago. 2008.

CUNHA, M. B. da. Construindo o futuro: a biblioteca universitária brasileira em 2010. Revista Ciência da Informação, Brasília, v. 29, n. 1, p. 71-89, jan./abr. 2000.

CUNHA, M. B. da. Das bibliotecas convencionais às digitais: diferenças e convergências. Revista Perspectivas em Ciência da Informação, v. 13, n. 1 , p. 2-17, 2008.

CONWAY, P. Preservação do universo digital. 2. ed. Rio de Janeiro: Arquivo Nacional, 2001.

FIGUEIREDO, N. Novas tecnologias: impacto sobre a formação de coleções, Revista Perspectivas em Ciência da Informação, v. 1, n. 2, p. 245-254, 1996.

FONSECA, E. N. da. Introdução à biblioteconomia. 2. ed. Brasília: Briquet de Lemos, 2007. 
FUNDACENTRO. Trabalhando pela saúde de quem trabalha. São Paulo: Fundacentro, 2006. Folder.

KROEF, R. L. Conteúdo informacional coletivo e desenvolvimento de comunidades. 2009. 184 f. Tese (Doutorado em Ciência da Informação) Escola de Ciência da Informação, Universidade Federal de Minas Gerais, Belo Horizonte, 2009.

MARCELINO, S. C. Estudo de usuários e usabilidade de sites de bibliotecas especializadas: o caso da "Biblioteca On-line" do Instituto Nacional de Pesquisas Espaciais (INPE). Mogi das Cruzes, 2008. 184 f. Dissertação (Mestrado em Semiótica, Tecnologias de Informação e Educação) Universidade Braz Cubas, Mogi das Cruzes, 2008.

McDANIEL, C.; GATS, R. Pesquisa de marketing. São Paulo: Pioneira, 2003.

RAUPP, F. M.; BEUREN, I. M. Metodologia da pesquisa aplicável às ciências sociais. In: BEUREN, I. M. Como elaborar trabalhos monográficos em contabilidade: teoria e prática. São Paulo: Atlas, 2006. p. 76-97.

SANTOS, T.; VERGUIERO, W. Gerenciamento de informações para universidades corporativas. Perspectivas em ciências da Informação, Belo Horizonte, v. 7, n. 1, p. 79-91, jan./jun. 2002. 